\title{
ANÁLISIS DEL MÉTODO PARA CALIFICACIÓN DE SOFT- WARE QSOS PARA LA SELECCIÓN DE SOFTWARE APLICA- BLE A PROCESOS EDUCATIVOS
}

\author{
Galo Ramos', Jaime Páez
}

\section{RESUMEN}

En este documento se define y analiza el método QSOS, concebido para calificar, seleccionar y comparar el software de código libre y abierto de forma objetiva, trazable y argumentada, ampliando el trabajo realizado por Atos Origin. Se estudia también las posibilidades de extrapolar sus funcionalidades para analizar y seleccionar software para la aplicación en procesos educativos. El método QSOS está disponible bajo los términos de la GNU Free Documentation License.

\section{INTRODUCCIÓN}

A nivel empresarial, la decisión de optar por una solución de software, representa implicaciones muy extensas, que van desde los aspectos económicos, legales, sociales e incluso de cultura organizacional. La decisión comúnmente se toma conforme al análisis de las necesidades y limitaciones (técnicas, funcionales y estratégicas) que éste software puede representar. Dentro del contexto educativo, a todos los aspectos antes analizados, se suman aspectos relativos a la docencia, como la adaptabilidad al proceso educativo y las funcionalidades investigativas, inherentes a cada pieza de software; estos aspectos extra, deben ser correctamente evaluados al momento de seleccionar herramientas que se integren en los procesos formativos, dadas las necesidades específicas de la actividad académica.

Cuando se planea implementar una solución de software a nivel tanto empresarial como educativo es necesario definir una metodología de calificación y selección objetiva, estructurada y funcional, basada en criterios técnicos, por ejemplo, resulta de vital importancia examinar las limitaciones y riesgos del software; también es necesario contar con un método de calificación para establecer de manera cuantitativa las diferencias existentes entre los distintos candidatos, tanto en aspectos técnicos como funcionales y estratégicos.

\footnotetext{
${ }^{1}$ Universidad Tecnológica Equinoccial, Facultad de Ciencias de la Ingeniería, Av. Occidental y Mariana de Jesús. Quito, Ecuador.gramos@ute.edu.ec
} 
Para realizar éste tipo de análisis es necesario contemplar criterios relativos a:

- Requerimientos técnicos actuales y planificados.

- Requerimientos funcionales actuales y planificados.

- Sostenibilidad del software.

- Nivel de estabilidad del software.

- Gestión de los fallos de funcionamiento del software.

- Nivel de soporte disponible y previsto para el software

- Influencia en el desarrollo del software.

- Prospecciones funcionales del software evaluado.

Por lo tanto, para poder cuantificar y medir las posibilidades reales de implantación del software es necesario establecer un método de gestión de riesgos y calificación de software, que nos ofrezca la posibilidad de hacer comparaciones de software según los requisitos de las necesidades específicas que se generan dentro del contexto pedagógicos, en función de establecer criterios ponderados, en base a los cuales calificar el software y hacer una selección final de la manera más objetiva y beneficiosa.

\section{PROCESO GENERAL}

El proceso general diseñado en QSOS se compone de cuatro etapas definidos en ciclos iterativos (figura 1).

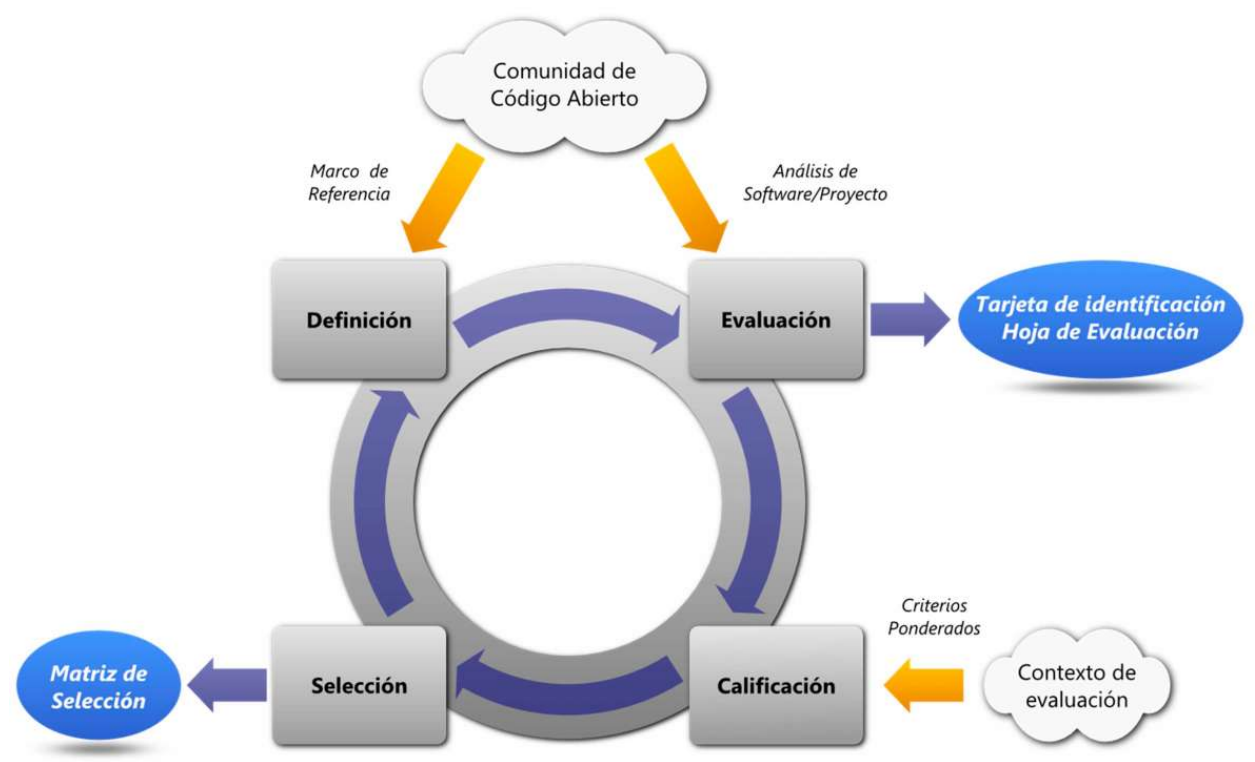

Figura 1. Etapas de QSOS. 
El proceso general de QSOS se puede aplicar con diferentes niveles de granularidad, lo que permite establecer el nivel de detalle del proceso en función de los requerimientos individuales de cada organización, así como el avance del proceso en ciclos iterativos para ir perfeccionando las cuatro etapas definidas.

\begin{tabular}{lll}
\hline Etapa & Descripción \\
\hline $1 \quad$ Definición & $\begin{array}{l}\text { Construcción de los marcos de referencia utilizados en las } \\
\text { etapas siguientes. }\end{array}$ \\
\hline 2 Evaluación & $\begin{array}{l}\text { Evaluación realizada en los tres ejes de criterios: cobertura } \\
\text { funcional, riesgos para el usuario y riesgos para el proveedor } \\
\text { de servicios. }\end{array}$ \\
\hline $\begin{array}{l}\text { Califica- } \\
\text { ción }\end{array}$ & $\begin{array}{l}\text { Ponderación de criterios divididos en los tres ejes, modelando } \\
\text { el contexto (requerimientos de los usuarios y/o estrategias } \\
\text { establecidas por el proveedor de servicios). }\end{array}$ \\
& $\begin{array}{l}\text { Aplicación del filtro creado en la Etapa 3, "Calificación" en } \\
\text { datos proporcionados por las dos primeras etapas, con el fin } \\
\text { de continuar las consultas, comparaciones y selecciones de } \\
\text { productos. }\end{array}$
\end{tabular}

Cuadro 1. Definición de etapas de QSOS.

\section{DEFINICIÓN}

En ésta etapa se deben definir los distintos elementos de la tipología reutilizados por las tres etapas restantes del proceso general, los marcos referenciales son:

- Familias de software: clasificación jerárquica de los dominios de software y la descripción de cuadros de funcionalidades asociados a cada dominio.

- Tipos de licencias: clasificación de licencias de código libre y abierto.

- Tipos de comunidades: clasificación de las organizaciones comunitarias existentes en torno al software de código abierto o libre y que son responsables de su ciclo de vida.

\section{Familias de software}

Este marco de referencia se desarrolla más, porque a medida que el software evoluciona ofrece nuevas funcionalidades que hay que añadir al marco de referencia. 


\section{Tipos de licencias}

Este marco de referencia lista y clasifica las licencias principales utilizadas para el software libre y de código abierto. Los criterios elegidos para describir dicha licencia son:

- Propiedad: Analiza si el código derivado puede convertirse en privativo o debe permanecer libre

- Viralidad: Analiza si alguno de los otros módulos vinculados al código fuente es inevitablemente afectado por la licencia

- Herencia: Analiza si el código derivado hereda su licencia obligatoriamente o es posible aplicar restricciones adicionales

El cuadro 2 muestra una comparación de las licencias más comunes que expone los criterios formulados anteriormente.

\begin{tabular}{|c|c|c|c|}
\hline Licencia & Propiedad & Viralidad & Herencia \\
\hline GPL & No & $\mathrm{Si}$ & $\mathrm{Si}$ \\
\hline LGPL & No & Parcial & $\mathrm{Si}$ \\
\hline BSD & $\mathrm{Si}$ & No & No \\
\hline Artistic & $\mathrm{Si}$ & No & No \\
\hline MIT & $\mathrm{Si}$ & No & No \\
\hline Apache vl.1 & $\mathrm{Si}$ & No & No \\
\hline Apache v2.0 & $\mathrm{Si}$ & No & No \\
\hline MPL v1.1 & No & No & $\mathrm{Si}$ \\
\hline Common Public License vl.1 & No & No & No \\
\hline Academic Free License v2.1 & $\mathrm{Si}$ & No & No \\
\hline PHP License v3.0 & $\mathrm{Si}$ & No & No \\
\hline Open Software License v2.0 & No & No & No \\
\hline Zope Public License v2.0 & $\mathrm{Si}$ & No & No \\
\hline Python SF License v2.0 & $\mathrm{Si}$ & No & No \\
\hline
\end{tabular}

Cuadro 2. Lista no exhaustiva de licencias de código abierto. 


\section{Tipos de comunidades}

Los tipos de comunidades identificadas de software libre se pueden clasificar así:

- Desarrollador aislado: el software es desarrollado y gestionado por una sola persona.

- Grupo de desarrolladores: varias personas colaboran de una manera informal.

- Organización de desarrolladores: un grupo de desarrolladores gestiona el ciclo de vida del software de una manera formal, generalmente basada en la asignación de funciones (desarrollador, tester, administrador de entrega...) y la meritocracia.

- Entidad legal: una persona jurídica (generalmente sin fines de lucro) que gestiona la comunidad, en general, posee derechos de autor y también gestiona el patrocinio y subvenciones vinculadas.

- Entidad comercial: la organización comercial emplea a los desarrolladores principales del proyecto que son remunerados mediante la venta de servicios o de versiones comerciales del software.

\section{EVALUACIÓN}

En ésta etapa se debe llevar a cabo la evaluación del software. Consiste en la recopilación de información de la comunidad de código abierto, con el fin de:

- Generar la tarjeta de identificación del software

- Generar la hoja de evaluación del software, al anotar criterios divididos en tres ejes principales:

- Cobertura funcional

- Riesgos desde la perspectiva del usuario

- Riesgos desde la perspectiva del proveedor de servicios

\section{Tarjeta de Identificación}

Los datos que constituyen la tarjeta de identificación son directos y objetivos, no se evalúan directamente sin embargo, se utilizan como base para el proceso de registro descrito a continuación.

Las partes principales de una tarjeta de identificación son:

\section{Información General}

- Nombre del software.

- Referencia, fecha de creación, fecha de publicación de la tarjeta de identificación.

- Autor. 
- Tipo de software.

- Breve descripción del software.

- Licencias a las cuales se encuentra sujeto el software.

- URL del proyecto y sitio de demostración.

- Sistemas operativos compatibles.

- Origen de la bifurcación (si el software es una bifurcación).

\section{Servicios existentes}

- Documentación.

- Cantidad de oferentes de soporte por contrato.

- Cantidad de oferentes de servicios de capacitación.

- Cantidad de oferentes de servicios de consultorías.

\section{Aspectos funcionales y técnicos}

- Tecnología(s) de implementación.

- Requisitos técnicos.

- Funcionalidades detalladas.

- Plan de trabajo.

\section{Síntesis}

- Tendencia general.

- Comentarios.

\section{Hoja de evaluación}

Cada versión del software se describe en una hoja de evaluación. Este documento incluye información más detallada que la tarjeta de identificación, ya que se centra en identificar, describir y analizar en detalle cada progreso presentada por la nueva versión.

\section{Puntuación}

Los criterios se puntúan de 0 a 2. Estas puntuaciones se utilizarán en la Etapa 4, "Selección” para comparar y seleccionar el software de acuerdo a las ponderaciones, representando las necesidades del usuario especificadas en la Etapa 3, "Calificación".

En los párrafos siguientes se describen los criterios utilizados para la puntuación de cada eje. Cabe señalar que el mismo criterio o criterios pueden parecer similares en distintos ejes. 


\section{Cobertura funcional}

El cuadro de funcionalidades se determina por la familia del software y el producto en el marco de referencia de la Etapa 1, "Definición". Para cada elemento del cuadro, la norma de puntuación es la siguiente:

\begin{tabular}{lc}
\hline Funcionalidad & Puntuación \\
\hline No Cubierta & 0 \\
Parcialmente cubierta & 1 \\
Completamente Cubierta & 2 \\
\hline
\end{tabular}

En algunos casos es necesario utilizar varios cuadros de funcionalidades para el mismo software, por ejemplo, cuando pertenece a más de una familia de software. En este caso, los criterios de funcionalidad se distribuyen en ejes separados con el fin de poder evaluar claramente la cobertura funcional para cada familia.

Los cuadros de funcionalidades deberán ser definidos conforme a los requerimientos de la organización y deberán ser aplicados en igualdad de condiciones para todo el software evaluado

\section{Riesgos desde la perspectiva del usuario}

Este eje de evaluación incluye criterios para estimar riesgos incurridos por el usuario cuando adopta software libre o de código abierto. La puntuación de los criterios se realiza independientemente de cualquier contexto de un usuario particular (el contexto es considerado después en la Etapa 3, "Calificación”).

Los criterios se dividen en cinco categorías:

- Durabilidad intrínseca

- Solución industrializada

- Integración

- Adaptabilidad técnica

- Estrategia

Los cuadros siguientes detallan cada una de estas categorías, especificando la regla de notación que se utilizará para cada criterio. 


\begin{tabular}{|c|c|c|c|c|}
\hline \multicolumn{2}{|c|}{ Durabilidad Intrínseca } & \multicolumn{3}{|l|}{ Puntuación } \\
\hline & & 0 & 1 & 2 \\
\hline \multirow[t]{4}{*}{ Madurez } & Edad & $\begin{array}{l}\text { Por ejemplo, menos } \\
\text { de } 3 \text { meses }\end{array}$ & $\begin{array}{l}\text { Por ejemplo, entre } 3 \\
\text { meses y } 3 \text { años }\end{array}$ & $\begin{array}{l}\text { Por ejemplo, ma- } \\
\text { yor a } 3 \text { años }\end{array}$ \\
\hline & Estabilidad & $\begin{array}{l}\text { Software inestable } \\
\text { con numerosas ver- } \\
\text { siones o parches que } \\
\text { generan efectos } \\
\text { secundarios }\end{array}$ & $\begin{array}{l}\text { Existen versiones de } \\
\text { producción, estables } \\
\text { pero antiguas. Difi- } \\
\text { cultades para estabi- } \\
\text { lizar versiones de } \\
\text { desarrollo }\end{array}$ & $\begin{array}{l}\text { Software estabili- } \\
\text { zado. Las versio- } \\
\text { nes proporcionan } \\
\text { correcciones de } \\
\text { errores, pero sobre } \\
\text { todo nuevas fun- } \\
\text { cionalidades }\end{array}$ \\
\hline & $\begin{array}{l}\text { Historial, problemas } \\
\text { conocidos }\end{array}$ & $\begin{array}{l}\text { Se conoce varios } \\
\text { problemas de soft- } \\
\text { ware que pueden ser } \\
\text { prohibitivos }\end{array}$ & $\begin{array}{l}\text { No hay problemas } \\
\text { conocidos o crisis }\end{array}$ & $\begin{array}{l}\text { Buena gestión } \\
\text { histórica de situa- } \\
\text { ciones criticas }\end{array}$ \\
\hline & $\begin{array}{l}\text { Probabilidad de } \\
\text { bifurcación, origen } \\
\text { de la bifurcación }\end{array}$ & $\begin{array}{l}\text { Es muy probable } \\
\text { que el software se } \\
\text { bifurque en un fu- } \\
\text { turo }\end{array}$ & $\begin{array}{l}\text { Software proviene } \\
\text { de una bifurcación, } \\
\text { pero tiene muy po- } \\
\text { cas posibilidades de } \\
\text { ser bifurcado en el } \\
\text { futuro }\end{array}$ & $\begin{array}{l}\text { Software cuenta } \\
\text { con muy pocas } \\
\text { posibilidades de } \\
\text { ser bifurcado. } \\
\text { Tampoco viene de } \\
\text { una bifurcación }\end{array}$ \\
\hline
\end{tabular}




\begin{tabular}{|c|c|c|c|c|}
\hline \multicolumn{2}{|c|}{ Durabilidad Intrínseca } & \multicolumn{3}{|l|}{ Puntuación } \\
\hline & & 0 & 1 & 2 \\
\hline \multirow[t]{5}{*}{ Adopción } & $\begin{array}{l}\text { Popularidad (en } \\
\text { relación a: público } \\
\text { en general, especia- } \\
\text { lizados...) }\end{array}$ & $\begin{array}{l}\text { Muy pocos usuarios } \\
\text { identificados }\end{array}$ & $\begin{array}{l}\text { Uso detectable me- } \\
\text { diante Internet } \\
\text { (SourceForge, } \\
\text { Freshmeat, Google.) }\end{array}$ & $\begin{array}{l}\text { Numerosos usua- } \\
\text { rios, numerosas } \\
\text { referencias }\end{array}$ \\
\hline & Referencias & Ninguno & $\begin{array}{l}\text { Pocas referencias, } \\
\text { usos no críticos }\end{array}$ & $\begin{array}{l}\text { A menudo imple- } \\
\text { mentado para } \\
\text { aplicaciones críti- } \\
\text { cas }\end{array}$ \\
\hline & $\begin{array}{l}\text { Contribuciones de la } \\
\text { comunidad }\end{array}$ & $\begin{array}{l}\text { Ninguna comunidad } \\
\text { o sin actividad real } \\
\text { (foro, lista de co- } \\
\text { rreo...) }\end{array}$ & $\begin{array}{l}\text { Comunidad exis- } \\
\text { tente con una nota- } \\
\text { ble actividad }\end{array}$ & $\begin{array}{l}\text { Fuerte comunidad: } \\
\text { gran actividad en } \\
\text { los foros, nume- } \\
\text { rosos colaborado- } \\
\text { res y defensores }\end{array}$ \\
\hline & Libros & $\begin{array}{l}\text { Ningún libro sobre } \\
\text { el software }\end{array}$ & $\begin{array}{l}\text { Al menos de cinco } \\
\text { libros sobre el soft- } \\
\text { ware disponibles }\end{array}$ & $\begin{array}{l}\text { Más de } 5 \text { libros } \\
\text { sobre el software } \\
\text { están disponibles } \\
\text { en varios idiomas }\end{array}$ \\
\hline & $\begin{array}{l}\text { Manuales y Tutoria- } \\
\text { les }\end{array}$ & $\begin{array}{l}\text { Muy pocos o ningún } \\
\text { manual o tutorial } \\
\text { sobre el software, o } \\
\text { los tutoriales son } \\
\text { poco relevantes y } \\
\text { confusos. }\end{array}$ & $\begin{array}{l}\text { Manuales o tutoria- } \\
\text { les con contenido } \\
\text { medianamente rele- } \\
\text { vante y poco con- } \\
\text { fuso }\end{array}$ & $\begin{array}{l}\text { Manuales o tuto- } \\
\text { riales sobre el tema } \\
\text { con contenido } \\
\text { relevante y dispo- } \\
\text { nibles en varios } \\
\text { idiomas }\end{array}$ \\
\hline
\end{tabular}

\begin{tabular}{|c|c|c|c|c|c|}
\hline \multirow{2}{*}{\multicolumn{3}{|c|}{ Durabilidad Intrínseca }} & \multicolumn{3}{|l|}{ Puntuación } \\
\hline & & & 0 & 1 & 2 \\
\hline \multirow[t]{2}{*}{$\begin{array}{l}\text { Dirección } \\
\text { Desarrollos }\end{array}$} & de & Equipo Principal & $\begin{array}{l}1 \text { a } 2 \text { individuos } \\
\text { involucrados, no } \\
\text { claramente identifi- } \\
\text { cados }\end{array}$ & $\begin{array}{l}\text { Entre } 2 \text { y } 5 \text { personas } \\
\text { independientes }\end{array}$ & Más de 5 personas \\
\hline & & Estilo de gestión & Dictadura total & $\begin{array}{l}\text { Despotismo ilus- } \\
\text { trado }\end{array}$ & $\begin{array}{l}\text { Consejo de arqui- } \\
\text { tectos con un líder } \\
\text { identificado (por } \\
\text { ejemplo: ASF...) }\end{array}$ \\
\hline
\end{tabular}




\begin{tabular}{|c|c|c|c|c|}
\hline \multicolumn{2}{|c|}{ Durabilidad Intrínseca } & \multicolumn{3}{|l|}{ Puntuación } \\
\hline & & 0 & 1 & 2 \\
\hline \multirow[t]{4}{*}{ Actividad } & $\begin{array}{l}\text { Número de desarro- } \\
\text { lladores, identifica- } \\
\text { ción, volumen de } \\
\text { negocios }\end{array}$ & $\begin{array}{l}\text { Menos de } 3 \text { desarro- } \\
\text { lladores, no clara- } \\
\text { mente identificados }\end{array}$ & $\begin{array}{l}\text { Entre } 4 \text { y } 7 \text { desarro- } \\
\text { lladores o más, no } \\
\text { identificados con } \\
\text { volumen de nego- } \\
\text { cios significativo }\end{array}$ & $\begin{array}{l}\text { Más de } 7 \text { desarro- } \\
\text { lladores claramente } \\
\text { identificados, } \\
\text { equipo muy estable }\end{array}$ \\
\hline & Actividad en errores & $\begin{array}{l}\text { Lenta o ninguna } \\
\text { reacción en el foro o } \\
\text { en la lista de correo } \\
\text { con respecto a las } \\
\text { correcciones de } \\
\text { errores en las notas } \\
\text { de lanzamiento }\end{array}$ & $\begin{array}{l}\text { Actividad detectable, } \\
\text { pero sin un proceso } \\
\text { claramente expues- } \\
\text { to, tiempo de reac- } \\
\text { ción y resolución } \\
\text { largo }\end{array}$ & $\begin{array}{l}\text { Reacción fuerte, } \\
\text { basado en roles y } \\
\text { asignación de ta- } \\
\text { reas }\end{array}$ \\
\hline & $\begin{array}{l}\text { Actividad en fun- } \\
\text { cionalidades }\end{array}$ & $\begin{array}{l}\text { Ninguna o pocas } \\
\text { funcionalidades } \\
\text { nuevas }\end{array}$ & $\begin{array}{l}\text { Progreso del soft- } \\
\text { ware impulsado por } \\
\text { el equipo central o } \\
\text { por solicitud del } \\
\text { usuario sin ningún } \\
\text { tipo de proceso } \\
\text { claramente explica- } \\
\text { do }\end{array}$ & $\begin{array}{l}\text { Herramienta(s) } \\
\text { para gestionar las } \\
\text { peticiones de ca- } \\
\text { racterísticas, una } \\
\text { fuerte interacción } \\
\text { con el plan de } \\
\text { trabajo }\end{array}$ \\
\hline & $\begin{array}{l}\text { Actividades en pu- } \\
\text { blicaciones }\end{array}$ & $\begin{array}{l}\text { Muy débil actividad } \\
\text { en ambas versiones, } \\
\text { producción y desa- } \\
\text { rrollo }\end{array}$ & $\begin{array}{l}\text { Actividad en ver- } \\
\text { siones de produc- } \\
\text { ción y desarrollo. } \\
\text { Frecuentes versiones } \\
\text { menores (corrección } \\
\text { de errores) }\end{array}$ & $\begin{array}{l}\text { Importante activi- } \\
\text { dad con frecuentes } \\
\text { versiones menores } \\
\text { (corrección de } \\
\text { errores) y versio- } \\
\text { nes principales } \\
\text { planificada en } \\
\text { relación con el plan } \\
\text { de trabajo }\end{array}$ \\
\hline
\end{tabular}

\begin{tabular}{|c|c|c|c|c|c|}
\hline \multicolumn{3}{|c|}{ Durabilidad Intrínseca } & \multicolumn{3}{|l|}{ Puntuación } \\
\hline & & & 0 & 1 & 2 \\
\hline $\begin{array}{l}\text { Independencia } \\
\text { de desarrollo }\end{array}$ & $\begin{array}{l}\text { Independencia } \\
\text { desarrollo }\end{array}$ & de & $\begin{array}{l}\text { Desarrollos realiza- } \\
\text { dos al } 100 \% \text { por los } \\
\text { empleados de una } \\
\text { sola empresa }\end{array}$ & Máximo $60 \%$ & Máximo 20\% \\
\hline
\end{tabular}




\begin{tabular}{|c|c|c|c|c|}
\hline \multicolumn{2}{|c|}{ Solución industrializada } & \multicolumn{3}{|l|}{ Puntuación } \\
\hline & & 0 & 1 & 2 \\
\hline \multirow[t]{3}{*}{ Servicios } & Capacitación & $\begin{array}{l}\text { Ninguna oferta de } \\
\text { capacitación identi- } \\
\text { ficada }\end{array}$ & $\begin{array}{l}\text { Existe oferta, pero } \\
\text { está limitada geográ- } \\
\text { ficamente, en tér- } \\
\text { minos de lenguaje o } \\
\text { suministrado por un } \\
\text { proveedor único }\end{array}$ & $\begin{array}{l}\text { Amplia oferta, } \\
\text { brindada por va- } \\
\text { rios proveedores } \\
\text { en varios idiomas y } \\
\text { se divide en mó- } \\
\text { dulos de niveles } \\
\text { graduales }\end{array}$ \\
\hline & Soporte & $\begin{array}{l}\text { Ninguna oferta de } \\
\text { soporte, excepto a } \\
\text { través de foros pú- } \\
\text { blicos y listas de } \\
\text { correo }\end{array}$ & $\begin{array}{l}\text { Existe oferta, pero } \\
\text { se limita a un único } \\
\text { proveedor sin un } \\
\text { fuerte compromiso } \\
\text { con la resolución } \\
\text { oportuna de los } \\
\text { incidentes }\end{array}$ & $\begin{array}{l}\text { Múltiples provee- } \\
\text { dores de servicios } \\
\text { con un fuerte } \\
\text { compro miso (por } \\
\text { ejemplo: tiempo de } \\
\text { resolución garan- } \\
\text { tizado) }\end{array}$ \\
\hline & Consultoría & $\begin{array}{l}\text { Ninguna oferta de } \\
\text { servicios de consul- } \\
\text { toría }\end{array}$ & $\begin{array}{l}\text { Servicios ofrecido } \\
\text { por un proveedor } \\
\text { único, limitado a } \\
\text { nivel del idioma y la } \\
\text { geografía }\end{array}$ & $\begin{array}{l}\text { Servicios de con- } \\
\text { sultoría prestados } \\
\text { por contratistas } \\
\text { distintos en varios } \\
\text { idiomas }\end{array}$ \\
\hline
\end{tabular}

\section{Solución industrializada}

Documentación Documentación

\section{Puntuación}

0

Ninguna documentación de usuario

\section{1}

Existe documentación, pero ha cambiado a través del tiempo, limitada en términos de idioma o le falta detalle

\section{2}

Documentación siempre actualizada y traducida, posiblemente adaptada para distintos lectores objetivo (usuario final, gerente, administrador de sistemas, etc.) 


\begin{tabular}{|c|c|c|c|c|}
\hline \multicolumn{2}{|c|}{ Solución industrializada } & \multicolumn{3}{|l|}{ Puntuación } \\
\hline & & 0 & 1 & 2 \\
\hline \multirow[t]{2}{*}{$\begin{array}{l}\text { Aseguramiento } \\
\text { de la Calidad }\end{array}$} & $\begin{array}{l}\text { Aseguramiento de la } \\
\text { Calidad }\end{array}$ & $\begin{array}{l}\text { Ningún proceso de } \\
\text { control de calidad }\end{array}$ & $\begin{array}{l}\text { Se identifican pro- } \\
\text { cesos de control de } \\
\text { calidad, pero no muy } \\
\text { formalizados y sin } \\
\text { hacer uso de ningu- } \\
\text { na herramienta }\end{array}$ & $\begin{array}{l}\text { Proceso automá- } \\
\text { tico de pruebas } \\
\text { incluido en el ciclo } \\
\text { de vida del código } \\
\text { con la publicación } \\
\text { de resultados }\end{array}$ \\
\hline & Herramientas & $\begin{array}{l}\text { Ninguna herra- } \\
\text { mienta de gestión } \\
\text { para reportes de } \\
\text { errores o solicitud de } \\
\text { funciones }\end{array}$ & $\begin{array}{l}\text { Proporcionada he- } \\
\text { rramientas estándar } \\
\text { (por ejemplo, un } \\
\text { repositorio SVN), } \\
\text { pero mal utilizadas }\end{array}$ & $\begin{array}{l}\text { Uso muy activo de } \\
\text { herramientas de } \\
\text { asignación de fun- } \\
\text { ciones/tareas y } \\
\text { seguimiento de } \\
\text { avances }\end{array}$ \\
\hline
\end{tabular}




\begin{tabular}{|c|c|c|c|c|}
\hline \multicolumn{2}{|c|}{ Solución industrializada } & \multicolumn{3}{|l|}{ Puntuación } \\
\hline & & 0 & 1 & 2 \\
\hline \multirow[t]{7}{*}{ Empaquetado } & Código Fuente & $\begin{array}{l}\text { El software no se } \\
\text { puede instalar desde } \\
\text { el código fuente sin } \\
\text { mucho trabajo }\end{array}$ & $\begin{array}{l}\text { Instalación desde la } \\
\text { fuente es limitada y } \\
\text { depende de condi- } \\
\text { ciones muy estrictas } \\
\text { (sistema operativo, } \\
\text { archivos, bibliote- } \\
\text { cas...) }\end{array}$ & $\begin{array}{l}\text { La instalación } \\
\text { desde el código } \\
\text { fuente es fácil }\end{array}$ \\
\hline & Debian & $\begin{array}{l}\text { El software no está } \\
\text { empaquetado para } \\
\text { Debian }\end{array}$ & $\begin{array}{l}\text { Existe un paquete } \\
\text { Debian, pero tiene } \\
\text { problemas impor- } \\
\text { tantes o no tiene } \\
\text { soporte oficial }\end{array}$ & $\begin{array}{l}\text { El software se } \\
\text { empaqueta en la } \\
\text { distribución }\end{array}$ \\
\hline & RedHat/Fedora & $\begin{array}{l}\text { El software no está } \\
\text { empaquetado para } \\
\text { RedHat/Fedora }\end{array}$ & $\begin{array}{l}\text { Existe un paquete, } \\
\text { pero tiene proble- } \\
\text { mas importantes o } \\
\text { no tiene soporte } \\
\text { oficial }\end{array}$ & $\begin{array}{l}\text { El software se } \\
\text { empaqueta en la } \\
\text { distribución }\end{array}$ \\
\hline & $\begin{array}{l}\text { Otra distribución } \\
\text { Linux Requerida }\end{array}$ & $\begin{array}{l}\text { El software no está } \\
\text { empaquetado para la } \\
\text { distribución reque- } \\
\text { rida }\end{array}$ & $\begin{array}{l}\text { Existe un paquete, } \\
\text { pero tiene proble- } \\
\text { mas importantes o } \\
\text { no tiene soporte } \\
\text { oficial }\end{array}$ & $\begin{array}{ll}\text { El software se } \\
\text { empaqueta en la } \\
\text { distribución }\end{array}$ \\
\hline & MacOS X & $\begin{array}{l}\text { El software no está } \\
\text { empaquetado para } \\
\text { MacOS X }\end{array}$ & $\begin{array}{l}\text { Existe un paquete, } \\
\text { pero tiene proble- } \\
\text { mas importantes o } \\
\text { no tiene soporte } \\
\text { oficial }\end{array}$ & $\begin{array}{l}\text { Existe un paquete } \\
\text { oficial de instala- } \\
\text { ción para MacOS } \\
\mathrm{X}\end{array}$ \\
\hline & Windows & $\begin{array}{l}\text { El proyecto no se } \\
\text { puede instalar en } \\
\text { Windows }\end{array}$ & $\begin{array}{l}\text { Existe un paquete, } \\
\text { pero es limitado o } \\
\text { tiene problemas } \\
\text { importantes o sólo } \\
\text { cubre versiones } \\
\text { específicas de Win- } \\
\text { dows (por ejemplo: } \\
\text { Windows 2000 y } \\
\text { Windows XP) }\end{array}$ & $\begin{array}{l}\text { Es totalmente } \\
\text { compatible con } \\
\text { Windows y se } \\
\text { proporciona un } \\
\text { paquete de instala- } \\
\text { ción }\end{array}$ \\
\hline & Otro S.O. & $\begin{array}{l}\text { El software no está } \\
\text { empaquetado para el } \\
\text { S.O. requerido }\end{array}$ & $\begin{array}{l}\text { Existe un paquete, } \\
\text { pero tiene proble- } \\
\text { mas importantes o } \\
\text { no tiene soporte } \\
\text { oficial }\end{array}$ & $\begin{array}{l}\text { Existe un paquete } \\
\text { oficial de instala- } \\
\text { ción para el S.O. } \\
\text { requerido }\end{array}$ \\
\hline
\end{tabular}




\begin{tabular}{|c|c|c|c|c|}
\hline \multicolumn{2}{|c|}{ Solución industrializada } & \multicolumn{3}{|l|}{ Puntuación } \\
\hline & & 0 & 1 & 2 \\
\hline \multirow[t]{2}{*}{$\begin{array}{l}\text { Explotabilidad } \\
\text { ergonomía }\end{array}$} & Facilidad de uso, & $\begin{array}{l}\text { Difícil de usar, re- } \\
\text { quiere un conoci- } \\
\text { miento en profun- } \\
\text { didad de la funcio- } \\
\text { nalidad del software, } \\
\text { ergonomía austera y } \\
\text { muy técnica }\end{array}$ & $\begin{array}{l}\text { Facilidad de uso } \\
\text { dada por la asistencia } \\
\text { entre usuarios. Pre- } \\
\text { sencia de Interfaces } \\
\text { Hombre-Máquina. }\end{array}$ & $\begin{array}{l}\text { Software muy } \\
\text { orientado al usua- } \\
\text { rio: ayuda contex- } \\
\text { tual, Interfaz de } \\
\text { usuario atractiva y, } \\
\text { posiblemente, } \\
\text { gestión de temas }\end{array}$ \\
\hline & $\begin{array}{l}\text { Administración, } \\
\text { Supervisión }\end{array}$ & $\begin{array}{l}\text { Ninguna funciona- } \\
\text { lidad de administra- } \\
\text { ción o de supervi- } \\
\text { sión }\end{array}$ & $\begin{array}{l}\text { Existen funcionali- } \\
\text { dades pero están } \\
\text { incompletas y re- } \\
\text { quieren ser mejora- } \\
\text { das }\end{array}$ & $\begin{array}{l}\text { Funcionalidades } \\
\text { administrativas y } \\
\text { de supervisión, } \\
\text { completas y fáciles } \\
\text { de usar. Posible } \\
\text { integración con } \\
\text { herramientas ex- } \\
\text { ternas (por ejem- } \\
\text { plo: a través de } \\
\text { SNMP, etc.) }\end{array}$ \\
\hline
\end{tabular}

\section{Adaptabilidad Técnica}

Modularidad Modularidad

\section{Puntuación}

0

Software Monolítico

\section{1}

Presencia de módulos de alto nivel que permiten un primer nivel de adaptación de software

\section{2}

Concepción modular, lo que permite una fácil adaptación del software mediante la selección de módulos o incluso el desarrollo de módulos nuevos 


\begin{tabular}{|c|c|c|c|c|}
\hline \multicolumn{2}{|c|}{ Adaptabilidad Técnica } & \multicolumn{3}{|l|}{ Puntuación } \\
\hline & & 0 & 1 & 2 \\
\hline \multirow[t]{2}{*}{$\begin{array}{l}\text { Trabajos deriva- } \\
\text { dos }\end{array}$} & $\begin{array}{l}\text { Modificación de } \\
\text { código }\end{array}$ & Todo a mano & $\begin{array}{l}\text { Recompilación po- } \\
\text { sible, pero compleja } \\
\text { sin ninguna herra- } \\
\text { mienta o documen- } \\
\text { tación }\end{array}$ & $\begin{array}{l}\text { Recompilación } \\
\text { con herramientas } \\
\text { (por ejemplo: ma- } \\
\text { ke, ANT...) y do- } \\
\text { cumentación pro- } \\
\text { porcionada }\end{array}$ \\
\hline & Extensión de código & $\begin{array}{l}\text { Cualquier modifica- } \\
\text { ción requiere la } \\
\text { recompilación del } \\
\text { código }\end{array}$ & $\begin{array}{l}\text { Arquitectura dise- } \\
\text { ñada para extensión } \\
\text { estática pero re- } \\
\text { quiere recompila- } \\
\text { ción }\end{array}$ & $\begin{array}{l}\text { Principio de plu- } \\
\text { gin, arquitectura } \\
\text { diseñada para la } \\
\text { extensión dinámica } \\
\text { sin necesidad de } \\
\text { recompilar }\end{array}$ \\
\hline
\end{tabular}

\section{Estrategia}

Licencia

\section{Puntuación}

0

Protección contra bifurcaciones propietarias

\section{Licencia muy per-} misiva como BSD o Apache License

12

Licencia moderadamente permisiva, situada entre ambos extremos (GPL y BSD), licencia dual en función del tipo de usuario (persona, empresa.) o de sus actividades
Licencia muy estricta, como la GPL

\section{Puntuación}

del Derechos en manos de unos pocos individuos o entidades, por lo que es más fácil cambiar la licencia

\begin{tabular}{lll}
\hline Estrategia & & Puntuación \\
\cline { 3 - 3 } $\begin{array}{l}\text { Propietarios del } \\
\text { copyright }\end{array}$ & $\begin{array}{l}\text { Propietarios del } \\
\text { copyright }\end{array}$ & $\begin{array}{l}\text { Derechos en manos } \\
\text { de unos pocos indi- } \\
\text { viduos o entidades, } \\
\text { por lo que es más } \\
\text { fácil cambiar la li- } \\
\text { cencia }\end{array}$
\end{tabular}
copyright
Propietarios del Propietarios

\section{2}

Derechos en manos de muchas personas, poseen el código de una manera homogénea, lo que hace muy difícil modificar la licencia
Derechos en manos de una persona jurídica en quien confía la comunidad (por ejemplo, la FSF o ASF) 


\begin{tabular}{|c|c|c|c|c|c|}
\hline \multirow[t]{2}{*}{ Estrategia } & & & \multicolumn{3}{|l|}{ Puntuación } \\
\hline & & & 0 & 1 & 2 \\
\hline $\begin{array}{l}\text { Modificación del } \\
\text { código fuente }\end{array}$ & $\begin{array}{l}\text { Modificación } \\
\text { código fuente }\end{array}$ & del & $\begin{array}{l}\text { Ninguna forma } \\
\text { práctica para pro- } \\
\text { poner modificacio- } \\
\text { nes del código }\end{array}$ & $\begin{array}{l}\text { Proporciona herra- } \\
\text { mientas para acceder } \\
\text { y modificar el código } \\
\text { (como CVS o SVN), } \\
\text { pero no se han usa- } \\
\text { do realmente para el } \\
\text { desarrollo del soft- } \\
\text { ware }\end{array}$ & $\begin{array}{l}\text { El proceso de } \\
\text { modificación del } \\
\text { código está bien } \\
\text { definido, expuesto } \\
\text { y respetado, me- } \\
\text { diante la asigna- } \\
\text { ción de funciones }\end{array}$ \\
\hline
\end{tabular}

\begin{tabular}{llll}
\hline Estrategia & Puntuación & & \\
\cline { 3 - 4 } Plan de trabajo & 0 & 1 & 2 \\
& Plan de trabajo & $\begin{array}{l}\text { Plan de trabajo no } \\
\text { publicado }\end{array}$ & $\begin{array}{l}\text { Existe un plan de Plan de trabajo } \\
\text { trabajo sin proyec- versionado, con } \\
\text { ción }\end{array}$ \\
proyección y me- \\
dida del retrasos
\end{tabular}

\begin{tabular}{|c|c|c|c|c|}
\hline \multirow[t]{2}{*}{ Estrategia } & & \multicolumn{3}{|l|}{ Puntuación } \\
\hline & & 0 & 1 & 2 \\
\hline Patrocinador & Patrocinador & $\begin{array}{l}\text { Software no tiene un } \\
\text { patrocinador, el } \\
\text { equipo principal no } \\
\text { es remunerado }\end{array}$ & $\begin{array}{l}\text { El software tiene un } \\
\text { patrocinador único } \\
\text { el cual determina las } \\
\text { estrategias }\end{array}$ & $\begin{array}{l}\text { El software es } \\
\text { patrocinado por la } \\
\text { industria }\end{array}$ \\
\hline
\end{tabular}

\begin{tabular}{|c|c|c|c|c|c|}
\hline \multirow[t]{2}{*}{ Estrategia } & & & \multicolumn{3}{|l|}{ Puntuación } \\
\hline & & & 0 & 1 & 2 \\
\hline $\begin{array}{l}\text { Independencia } \\
\text { estratégica }\end{array}$ & $\begin{array}{l}\text { Independencia } \\
\text { tratégica }\end{array}$ & es- & $\begin{array}{l}\text { Estrategia no detec- } \\
\text { table o fuerte de- } \\
\text { pendencia de un } \\
\text { actor único (perso- } \\
\text { na, compañía, pa- } \\
\text { trocinador.) }\end{array}$ & $\begin{array}{l}\text { Visión estratégica } \\
\text { compartida con } \\
\text { otros proyectos de } \\
\text { código libre y } \\
\text { abierto, pero sin un } \\
\text { fuerte compromiso } \\
\text { de los propietarios } \\
\text { de derechos de autor }\end{array}$ & $\begin{array}{l}\text { Independencia } \\
\text { fuerte del equipo } \\
\text { principal, la enti- } \\
\text { dad titular de los } \\
\text { derechos legales } \\
\text { participa activa- } \\
\text { mente en el pro- } \\
\text { ceso de normaliza- } \\
\text { ción }\end{array}$ \\
\hline
\end{tabular}




\section{Riesgos desde la perspectiva del proveedor de servicios}

Este eje incluye los criterios de evaluación para los riesgos incurridos por un proveedor de servicios alrededor del software de código abierto (conocimientos, integración, desarrollo, apoyo.). Es especialmente sobre esta base se puede determinar su nivel de compromiso.

\begin{tabular}{|c|c|c|c|c|}
\hline \multicolumn{2}{|c|}{ Prestación de servicios } & \multicolumn{3}{|l|}{ Puntuación } \\
\hline & & 0 & 1 & 2 \\
\hline \multirow[t]{4}{*}{ Mantenibilidad } & $\begin{array}{l}\text { Calidad del código } \\
\text { fuente }\end{array}$ & $\begin{array}{l}\text { Código no muy } \\
\text { legible o de mala } \\
\text { calidad, incoheren- } \\
\text { cia en los estilos } \\
\text { codificación }\end{array}$ & $\begin{array}{l}\text { Código legible, pero } \\
\text { realmente no co- } \\
\text { mentado en detalle }\end{array}$ & $\begin{array}{l}\text { Código legible. } \\
\text { Patrones de diseño } \\
\text { estándar, imple- } \\
\text { mentados y co- } \\
\text { mentados. Políti- } \\
\text { cas de codifica- } \\
\text { ción, coherentes y } \\
\text { respetadas }\end{array}$ \\
\hline & $\begin{array}{l}\text { Dispersión tecnoló- } \\
\text { gica }\end{array}$ & $\begin{array}{l}\text { Uso de múltiples } \\
\text { lenguajes distintos }\end{array}$ & $\begin{array}{l}\text { Un lenguaje princi- } \\
\text { pal con ciertos mó- } \\
\text { dulos codificados en } \\
\text { otros lenguajes para } \\
\text { requisitos específi- } \\
\text { cos y limitados }\end{array}$ & Lenguaje Único \\
\hline & $\begin{array}{l}\text { Complejidad In- } \\
\text { trínseca }\end{array}$ & $\begin{array}{l}\text { Código muy com- } \\
\text { plejo que requiere } \\
\text { alto nivel de cono- } \\
\text { cimientos para llevar } \\
\text { a cabo modifica- } \\
\text { ciones sin generar } \\
\text { efectos secundarios }\end{array}$ & $\begin{array}{l}\text { Código no muy } \\
\text { complejo, pero } \\
\text { requiere conoci- } \\
\text { mientos en lenguajes } \\
\text { de programación y } \\
\text { diseño de software }\end{array}$ & $\begin{array}{l}\text { Codificación y } \\
\text { diseño simples, } \\
\text { fácil de modificar }\end{array}$ \\
\hline & $\begin{array}{l}\text { Documentación } \\
\text { técnica }\end{array}$ & $\begin{array}{l}\text { Ninguna documen- } \\
\text { tación (guía de } \\
\text { desarrollo o docu- } \\
\text { mentación generada } \\
\text { automática mente } \\
\text { como javadoc) }\end{array}$ & $\begin{array}{l}\text { Documentación } \\
\text { incompleta o anti- } \\
\text { gua, sin considera- } \\
\text { ciones de arquitec- } \\
\text { tura integradas }\end{array}$ & $\begin{array}{l}\text { Documentación } \\
\text { detallada y actua- } \\
\text { lizada, incluyendo } \\
\text { consideraciones de } \\
\text { arquitectura, dise- } \\
\text { ño y codificación }\end{array}$ \\
\hline
\end{tabular}




\begin{tabular}{|c|c|c|c|c|c|}
\hline \multirow{2}{*}{\multicolumn{3}{|c|}{ Prestación de servicios }} & \multicolumn{3}{|l|}{ Puntuación } \\
\hline & & & 0 & 1 & 2 \\
\hline \multirow{2}{*}{\multicolumn{2}{|c|}{$\begin{array}{l}\text { Dominio } \\
\text { código }\end{array}$}} & Directo & $\begin{array}{l}\text { Ninguna experiencia } \\
\text { directa con el código } \\
\text { fuente }\end{array}$ & $\begin{array}{l}\text { Dominio del código, } \\
\text { pero limitado a una } \\
\text { sola persona o una } \\
\text { sola parte del código } \\
\text { fuente }\end{array}$ & $\begin{array}{l}\text { Varios individuos } \\
\text { dominan el código } \\
\text { y cubren así la } \\
\text { totalidad del có- } \\
\text { digo fuente }\end{array}$ \\
\hline & & Indirecto & $\begin{array}{l}\text { Ninguna experiencia } \\
\text { indirecta con el } \\
\text { código fuente }\end{array}$ & $\begin{array}{l}\text { Fuerte dominio a } \\
\text { través de expertos } \\
\text { externos propor- } \\
\text { cionados por socios }\end{array}$ & $\begin{array}{l}\text { Colaboración con } \\
\text { el propietario de } \\
\text { los derechos de } \\
\text { autor y/o el equipo } \\
\text { principal }\end{array}$ \\
\hline
\end{tabular}

\section{Granularidad del registro}

Como se mencionó anteriormente es posible repetir el proceso general de manera iterativa. En la fase de evaluación esto trae como consecuencia la capacidad de evaluar criterios en tres ciclos, cambiando el nivel de granularidad dependiendo de la evaluación realizada, por lo tanto, es posible evaluar:

1. Categorías principales

2. Subcategorías de cada categoría

3. Criterios restantes (es decir, todo lo que no se encuentra incluido en los dos primeros ítems)

Esto permite no bloquear el avance del proceso general cuando no se dispone de todas las calificaciones.

Una vez que todos los criterios se han evaluado, las calificaciones de los dos primeros niveles se calculan utilizando una media ponderada de las calificaciones de los niveles anteriores.

\section{CALIFICACIÓN}

En ésta etapa se busca definir un conjunto de elementos que reflejan las necesidades y limitaciones relacionadas con el proceso de selección de un software de código abierto. Esto es para describir el contexto en el que se propone utilizar software libre, con el fin de obtener un filtro que se utiliza posteriormente en la Etapa 4, "Selección” del proceso general.

\section{Filtro en la tarjeta de identificación}

Un primer nivel de filtrado se puede definir en los datos de tarjeta de identificación del software. 
Por ejemplo, se podría considerar el software sólo de una determinada familia o software que es compatible con un sistema operativo determinado.

En general, aunque no es obligatorio, este filtro no incluye ninguna ponderación, sino que se utiliza sobre todo para eliminar el software inadecuado en el contexto específico del usuario, es decir, se utiliza para determinar características altamente limitantes (críticas), las cuales, por el hecho de no estar presentes, anulan totalmente la posibilidad de uso del software dentro del entorno de la organización.

\section{Filtro de cuadros de funcionalidades}

Todas las características del cuadro de funcionalidades se atribuyen un nivel de exigencia seleccionado entre los siguientes:

- Funcionalidad requerida

- Funcionalidad opcional

- Funcionalidad no requerida

Estos niveles de exigencia estarán relacionados a los valores de ponderación en la Etapa 4, "Selección”, según el modo elegido de selección.

\section{Filtro sobre los riesgos del usuario}

La relevancia de cada criterio de este eje se coloca de acuerdo al contexto del usuario, como se indica en el cuadro siguiente:

\begin{tabular}{l}
\hline Relevancia \\
\hline Criterio irrelevante, excluidos del filtro \\
Criterio relevante \\
Criterio crítico \\
\hline
\end{tabular}

Esta relevancia será convertida en un valor de ponderación numérica en la siguiente etapa, según el modo elegido de selección.

\section{Filtro sobre los riesgos del proveedor de servicios}

Este filtro es utilizado por un proveedor de servicios para evaluar software y servicios que serán integrados en su oferta y para determinar los niveles de compromiso relacionados. 


\section{SELECCIÓN}

En ésta etapa se busca seleccionar el software para satisfacer las necesidades del usuario, o más generalmente para comparar software similar.

Es posible realizar la selección mediante dos modos:

- Selección estricta

- Selección flexible

\section{Selección estricta}

La selección estricta se basa en la eliminación directa tan pronto como el software no cumple con los requisitos formulados en la Etapa 3, "Calificación”:

- Eliminación de software incompatible con el filtro de la tarjeta de identificación

- Eliminación de software que no proporciona la funcionalidad requerida por el filtro en el cuadro de funcionalidades

- Eliminación de software en que los criterios de riesgo utilizados no se ajustan a las normas establecidas por el usuario

- La puntuación de un criterio pertinente debe ser al menos igual a 1

- La puntuación de un criterio fundamental debe ser al menos igual a 2

Este método es muy selectivo y puede, en función de la exigencia del consumidor, no devolver ningún software como resultado.

El software que ha pasado la selección se le asigna una puntuación global determinada mediante la ponderación de la misma manera que en la selección flexible.

\section{Selección flexible}

Este método es menos estricto que el anterior, porque en lugar de eliminar el software no elegible, lo clasifica mientras mide la desviación en los filtros aplicados.

Las reglas de ponderación a utilizar se detallan en los párrafos siguientes.

\section{Ponderación de las funcionalidades}

El valor de ponderación se basa en el nivel de exigencia definida en cada funcionalidad del cuadro de funcionalidades. 


\begin{tabular}{ll}
\hline Nivel de exigencia & Ponderación \\
\hline Funcionalidad requerida & +3 \\
Funcionalidad opcional & +1 \\
Funcionalidad no requerida & 0 \\
\hline
\end{tabular}

Ponderación de riesgo en el eje del usuario

El valor de ponderación se basa en la relevancia de cada criterio en el eje de riesgo del usuario.

\begin{tabular}{ll}
\hline Relevancia & Ponderación \\
\hline Criterio irrelevante & 0 \\
Criterio relevante & $+10-1$ \\
Criterio crítico & $+30-3$ \\
\hline
\end{tabular}

El signo del valor ponderado representa un impacto positivo o negativo en relación a los requerimientos del usuario.

\section{Comparación}

El software de una misma familia (con un cuadro de funcionalidades común) también puede ser comparado en base a los puntajes ponderados determinados antes.

La figura 2 ilustra el tipo de síntesis disponibles. 


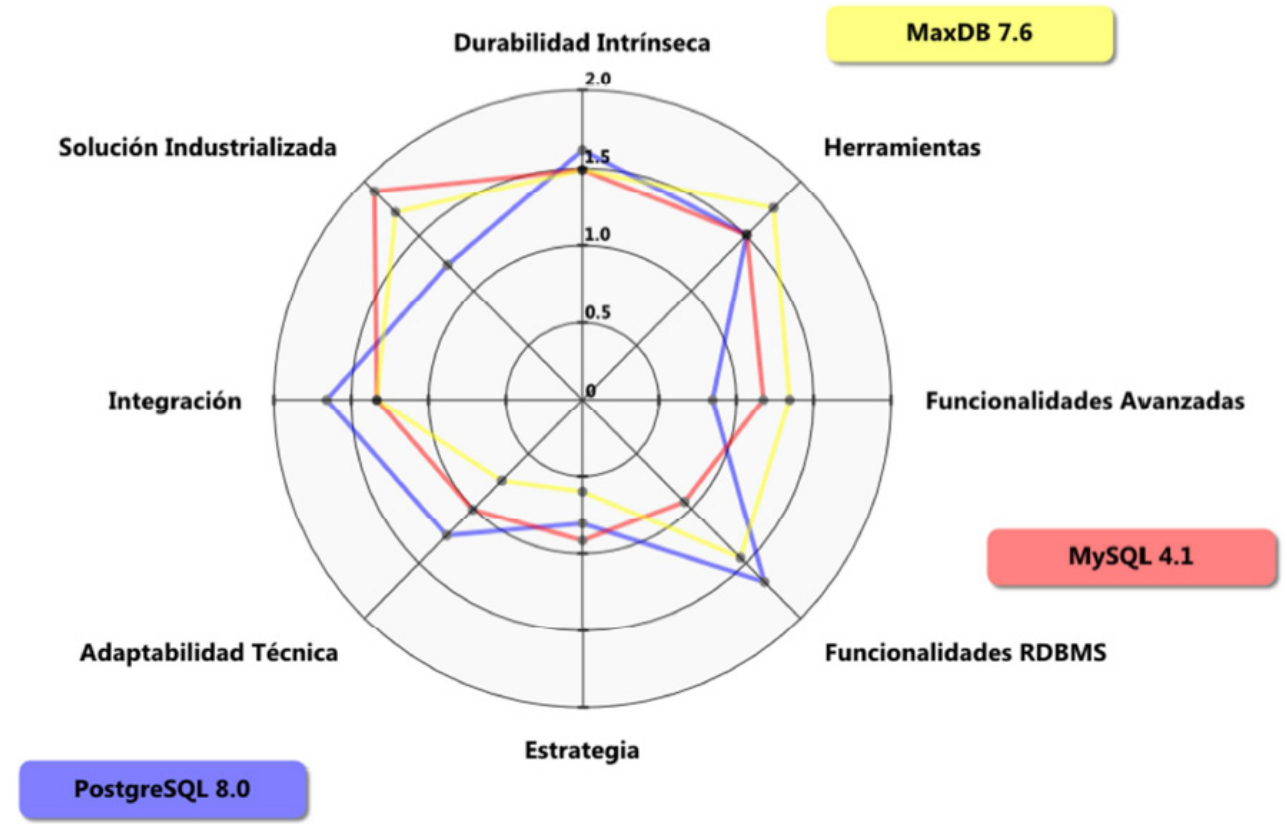

Figura 2. Comparación. Esta figura se presenta como un ejemplo, por lo que las ponderaciones en los distintos ejes no son representativas de todos contextos de uso de un RDMBS.

Así, evaluando dentro de un diagrama radial los resultados obtenidos, en cada uno de los dominios de software relevantes, podemos visualizar las fortalezas y debilidades de cada producto evaluado, y comparar las funcionalidades requeridas que sean más relevantes para organización.

\section{CONCLUSIÓN}

Dentro del ambiente académico el método QSOS debe ser ampliado para poder ser utilizado como parte del proceso de selección de software, dado que existen variables de entorno, referentes al contexto de aplicación profesional de las herramientas que utilicen los docentes, que el método QSOS no analiza; por ejemplo, la penetración del software a nivel empresarial, los formatos, estándares y capacidades tecnológicas propias de cada organización, los cuales deben ser anexados a los cuadros de funcionalidades propuestos de QSOS.

Adicionalmente, como una etapa previa a la aplicación de la metodología QSOS dentro de los ambiente académicos es necesario complementarla añadiéndole una etapa previa al Proceso General, que realice un análisis costo/beneficio, el cual, mida las implicaciones económicas de uso de software libre frente al software privativo, dado que, a diferencia de la creencia general, el uso de software libre o de 
fuentes abiertas, también ocasiona gastos a las organizaciones, simplemente que éstos gastos se encuentran focalizados en áreas distintas a las del software privativo.

Finalmente, el método QSOS, debe ser adaptado para cada una de las organizaciones donde se lo pretenda implantar tomando en cuenta las variables económicas, legales, sociales, organizacionales, tecnológicas y estratégicas particulares que puedan intervenir en el proceso. Por ejemplo, dentro de los países que hayan ratificado acuerdos internacionales o tengan legislaciones internas referentes a patentes de software, se deberá revisar el aspecto legal de aplicación de ciertas soluciones de software libre que han recibido cuestionamientos en este sentido. 